\title{
Changes in Monoamine Release in the Ventral Horn and Hypoglossal Nucleus Linked to Pontine Inhibition of Muscle Tone: An In Vivo Microdialysis Study
}

\author{
Yuan-Yang Lai, ${ }^{1}$ Tohru Kodama, ${ }^{1,2}$ and Jerome M. Siegel ${ }^{1}$ \\ ${ }^{1}$ Department of Psychiatry and Biobehavioral Neuroscience, School of Medicine, University of California Los Angeles, and \\ Veterans Affairs, Greater Los Angeles Health Care System Medical Center, North Hills, California 91343, and 2Department \\ of Psychology, Tokyo Metropolitan Institute of Neuroscience, Fuchu, Tokyo 183 8526, Japan
}

A complete suppression of muscle tone in the postural muscles and a reduction of muscle tone in the respiratory related musculature occur in rapid eye movement (REM) sleep. Previous studies have emphasized the role of glycine in generating these changes. Because the activity of norepinephrine- and serotonin-containing neurons is known to decrease in REM sleep, we hypothesized that a decrease in release in one or both of these transmitters might be detected at the motoneuronal level during muscle tone suppression elicited by brainstem stimulation in the decerebrate animal. We compared release in the ventral horn with that in the hypoglossal nucleus to determine whether the mechanism of muscle tone suppression differs in these nuclei as has been hypothesized. Electrical stimulation and cholinergic agonist injection into the mesopontine reticular formation produced a suppression of tone in the postural and respiratory muscles and simultaneously caused a significant reduction of norepinephrine and serotonin release of similar magnitude in both hypoglossal nucleus and spinal cord. Norepinephrine and serotonin release in the motoneuron pools was unchanged when the stimulation was applied to brainstem areas that did not generate bilateral suppression. No change in dopamine release in the motoneuron pools was seen during mesopontine stimulation-induced atonia. We hypothesize that the reduction of monoamine release that we observe exerts a disfacilitatory effect on both ventral horn and hypoglossal motoneurons and that this disfacilitatory mechanism contributes to the muscle atonia elicited in the decerebrate animal and in the intact animal during REM sleep.

Key words: decerebration; REM sleep; respiration; tongue; locus coeruleus; raphe nucleus; norepinephrine; serotonin; hypoglossal nucleus; spinal cord; sleep apnea
Magoun and Rhines (1946) discovered that stimulation of the medial medulla in the decerebrate animal produces a shortlatency inhibition of reflex response in skeletal muscle systems. More recently we found that the regions that generate muscle tone suppression by electrical stimulation extend from the medulla through the pons and into the caudal midbrain (Lai and Siegel, 1990, 1999). Electrical and chemical stimulation in the pontine inhibitory area (PIA; Lai et al., 1993), including the central portion of the nucleus pontis centralis oralis and caudalis, generates muscle tone suppression in the decerebrate animal (Lai and Siegel, 1988, 1991; Hajnik et al., 2000). In the chronic animal, the PIA can be chemically activated to produce a long period of REM sleep-like activity (George et al., 1964; Van Dongen et al., 1978; Lai and Siegel, 1988). Damage to this region produces REM sleep without atonia (Jouvet and Delorme, 1965; Henley and Morrison, 1974). A population of neurons in this area is selectively active in REM sleep (Sakai et al., 1981; Siegel et al., 1981). Thus, the PIA is part of the mechanism for generating REM sleep.

Electrical stimulation of the brainstem monoaminergic cell groups facilitates motoneuronal activity (Fung and Barnes, 1981,

\footnotetext{
Received March 26, 2001; revised June 26, 2001; accepted July 5, 2001.

This work supported by United States Public Health Service Grants HL 41370 and HL 60296 and the Department of Veterans Affairs.

Correspondence should be addressed to Y. Y. Lai, Neurobiology Research (151A3), Veterans Affairs, Greater Los Angeles Health Care System Sepulveda, 16111 Plummer Street, North Hills, CA 91343. E-mail: yylai@ucla.edu.

Copyright (C) 2001 Society for Neuroscience $0270-6474 / 01 / 217384-08 \$ 15.00 / 0$
}

1989; Lai et al., 1989; Nagase et al., 1997). Dopamine is also known to facilitate motoneuronal activity in the anesthetized cat (Baker and Anderson, 1972). Therefore, inactivation of monoaminergic system could elicit muscle tone suppression by disfacilitation. On the other hand, active inhibition by GABA and glycine has been shown to decrease both spinal and hypoglossal (XII) motoneuron excitability (Kawai and Sasaki, 1964; Bruggencate and Sonnhof, 1972; Soja et al., 1987, 1991; Yamuy et al., 1999). Kubin et al. (1993) concluded that the hypoglossal and possibly other cranial motoneurons had a different mechanism of motor inhibition than spinal motoneurons. They suggested that hypoglossal motoneurons were not subject to glycinergic inhibition but were inactivated by a reduction in serotonin $(5-\mathrm{HT})$ release during REM sleep (Kubin et al., 1993).

Therefore, we had two goals in the present study. The first was to determine whether stimulation of the inhibitory mesopontine region in the decerebrate animal produced a reduction in monoamine release by measuring norepinephrine (NE), 5-HT, and dopamine (DA) release. The second was to determine whether any observed changes in monoamine release were confined to the XII nucleus or whether they were also present in lumbar motoneuron pools. Collection of dialysates collected from multiple sites allowed us to simultaneously evaluate the role of monoamines in the control of cranial and spinal motoneuron activity.

\section{MATERIALS AND METHODS}

Animal preparation. Two male and five female young adult cats weighing from $2.5-3.5 \mathrm{~kg}$ were used. Tracheotomy, laminectomy, and decerebra- 


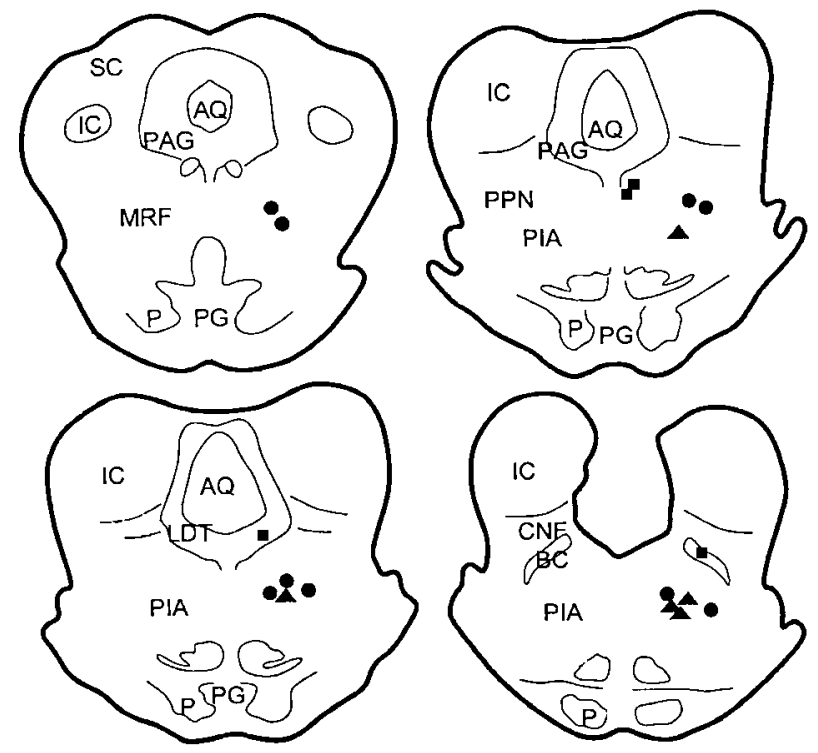

Figure 1. Histology showing the stimulation sites in the mesopontine reticular formation. Seven stimulation sites were on the left side of the brain. Dots (electrical stimulation) and triangles (both electrical and chemical stimulation) represent the sites in which stimulation elicited a bilateral reduction of muscle tone, whereas the sites from which stimulation failed to induce muscle tone suppression are marked by filled squares. $A Q$, Aqueduct; $B C$, brachium conjunctivum; $C N F$, cuneiform nucleus; $I C$, inferior colliculus; $L D T$, dorsolateral tegmental nucleus; $P$, pyramidal tract; $P A G$, periaqueductal gray; $P G$, pontine gray; $P I A$, pontine inhibitory area; $P P N$, pedunculopontine tegmental nucleus.

tion were performed while the animals were anesthetized with a halothane-oxygen mixture. Decerebration was done at the postmammillaryprecollicular level. The spinal cord was exposed from the $\mathrm{L}_{6}$ to $\mathrm{S}_{1}$ segments. The medial cerebellum was removed by aspiration to allow insertion of the microdialysis probes into the hypoglossal nucleus. Blood pressure was recorded from the femoral artery. Data collected from animals in which the mean arterial pressure remained $>80 \mathrm{mmHg}$ were analyzed. Rectal temperature was monitored through a thermoregulator connected to a heating pad and set to maintain the body temperature at $38 \pm 0.5^{\circ} \mathrm{C}$.

Stimulation and electromyogram recording. A bipolar stainless steel microelectrode (SNEX-100; David Kopf Instruments, Tujunga, CA) was used for mesopontine electrical stimulation. A 300 or $500 \mathrm{msec}$ train of $0.2 \mathrm{msec}, 100 \mathrm{~Hz}$, and 10-40 $\mu \mathrm{A}$ cathodal rectangular pulses was administered to the brainstem. When we identified a mesopontine site at which stimulation produced muscle tone suppression, stimulation with the same parameters was delivered once every $10 \mathrm{sec}$ for a period of $5 \mathrm{~min}$. Each site received two parametrically identical stimulations $2 \mathrm{hr}$ apart. Five of the electrical stimulation sites also received an injection of $0.5 \mu \mathrm{l}$ of $1 \mathrm{M}$ acetylcholine (Ach).

Muscles in the neck (occipitoscapularis and splenius), hindlimb (gastrocnemius), tongue (genioglossus), and diaphragm were implanted with bipolar multistranded stainless steel electromyogram (EMG) electrodes ( $2 \mathrm{~mm}$ uninsulated portions exposed and 4-6 $\mathrm{mm}$ interelectrode separation). EMG activity was integrated through a Grass integrator (model $7 \mathrm{P} 10 \mathrm{~F}$ ) and recorded polygraphically (Grass model 78E). The integrated muscle activity was measured for 5 min during the prestimulation period to determine baseline level and for 5 min during the stimulation period.

Microdialysis sampling. Microdialysis probes with a tip length of $1 \mathrm{~mm}$ (Type A-1-02; Eicom, Kyoto, Japan) were inserted into the XII nucleus, and another pair of probes with a tip length of $2 \mathrm{~mm} \mathrm{(59-7005;} \mathrm{Harvard}$ Apparatus, South Natick, MA) were inserted into the lumbar ventral horn bilaterally. Microdialysis probes were perfused with artificial CSF (Harvard Apparatus) at a flow rate of $2 \mu \mathrm{l} / \mathrm{min}$. Dialysates were collected for $5 \mathrm{~min}$ intervals during the prestimulation period, the stimulation period, and the poststimulation period. Ten microliters of dialysate were collected in each polypropylene sample tube under acidic conditions, $\mathrm{pH}$ 3.5 , at $10^{\circ} \mathrm{C}$. They were frozen at $-80^{\circ} \mathrm{C}$ within 5 min of collection. Experiments were started at least $3 \mathrm{hr}$ after the insertion of microdialysis probes and lasted for $24 \mathrm{hr}$.
Monoamine assay. The NE, DA, and 5-HT levels in the dialysates were determined by an HPLC and electrochemical detection $(450 \mathrm{mV})$ system (DTA-300; Eicom). The mobile phase for DA/5-HT was $80 \% 100 \mathrm{~mm}$ phosphate buffer, $\mathrm{pH} 6.0$, and $20 \%$ methanol, containing $500 \mathrm{mg} / \mathrm{l}$ octansulphonic acid and $50 \mathrm{mg} / 1$ EDTA-2Na. Norepinephrine was detected with a mobile phase consisting of $95 \% 100 \mathrm{~mm}$ phosphate buffer, $\mathrm{pH} 6.0$, and $5 \%$ methanol, containing $400 \mathrm{mg} / \mathrm{l}$ octansulphonic acid and $50 \mathrm{mg} / 1 \mathrm{EDTA}-2 \mathrm{Na}$. The detection limit of our analysis system was 0.5 fmol per $20 \mu \mathrm{l}$ injection.

Histology and data analysis. At the end of the study, a $50 \mu \mathrm{A}$ anodal direct current was delivered into the stimulation site through the stimulation electrode for $20 \mathrm{sec}$ to deposit iron. Animals were anesthetized with Nembutal (35 mg/ $\mathrm{kg}$, i.v.) and perfused intracardially with saline followed with buffered $10 \%$ formalin. Brain tissues were cut at $50 \mu \mathrm{m}$ and stained with Neutral Red. Sections were counterstained with ferrocyanide to detect the iron deposit. The collecting sites from the XII nucleus and spinal ventral horn were identified by the tracts of the microdialysis probe. The stimulation and dialysate collecting sites in the brainstem were reconstructed according to the atlas of Berman (1968).

\section{RESULTS}

\section{Stimulation and dialysate collection sites}

Electrical stimulation sites in the mesopontine area are presented in Figure 1. Ten of these sites were located in the PIA. The remaining stimulation sites were found in the caudal mesencephalic reticular formation (MRF; two sites), pedunculopontine tegmental nucleus (PPN; two sites), medial longitudinal bundle (MLB; two sites), dorsolateral tegmental nucleus (LDT; one site), and brachium conjunctium (BC; one site). The five sites that received Ach injection were located in the PIA (Fig. 1).

Figure 2 shows the location of the 15 microdialysis probes in the brainstem and 13 probes in the spinal cord. Eleven sites in the brainstem and eight sites in the spinal cord were used for electrical stimulation, whereas the rest of four sites in the brainstem and five sites in the spinal cord were used for the chemical

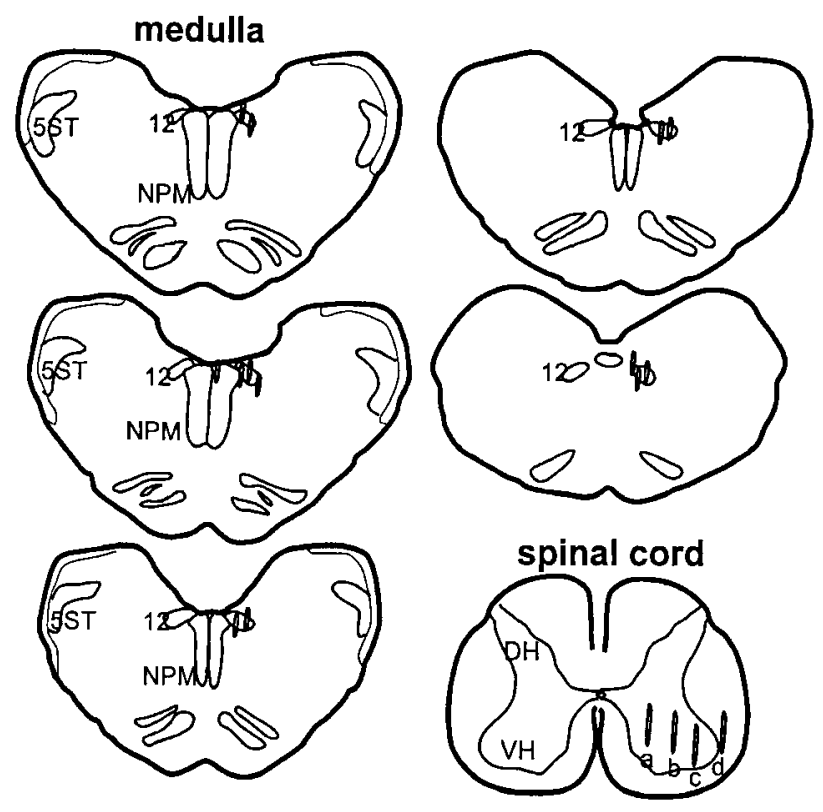

Figure 2. Histology showing the dialysate collecting sites in the brainstem and spinal cord. Dialysates were collected from both sides of hypoglossal nucleus and spinal cord. Among 12 dialysis probes found in the spinal ventral horn, three were located at position $a$, two probes were located at $b$, and seven probes were found at $c$. One probe $(d)$ was found in the lateroventral funiculus. $D H$, Dorsal horn; NPM, nucleus paramedianus; $V H$, ventral horn; $5 S T$, spinal trigeminal tract; 12 , hypoglossal nucleus. 
A

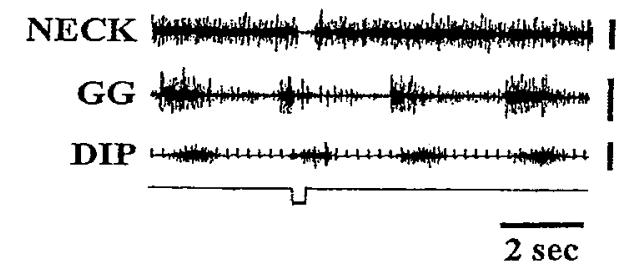

C applied into the pontine inhibitory area. Three types of muscle tone suppression, a short $(A)$, a prolonged $(B)$ suppression, and atonia $(C)$, in the neck muscle could be induced by mesopontine stimulation. However, a prolonged suppression in the genioglossus and a short period of suppression in the diaphragm were seen in all cases. DIP, diaphragm; $G G$, genioglossus muscle.
B

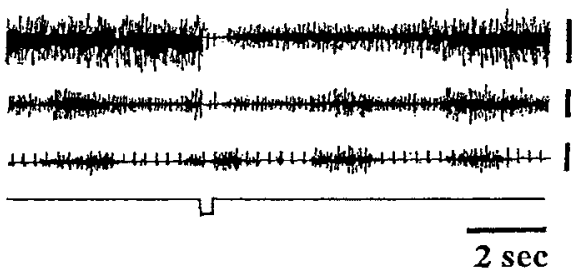

$2 \sec$

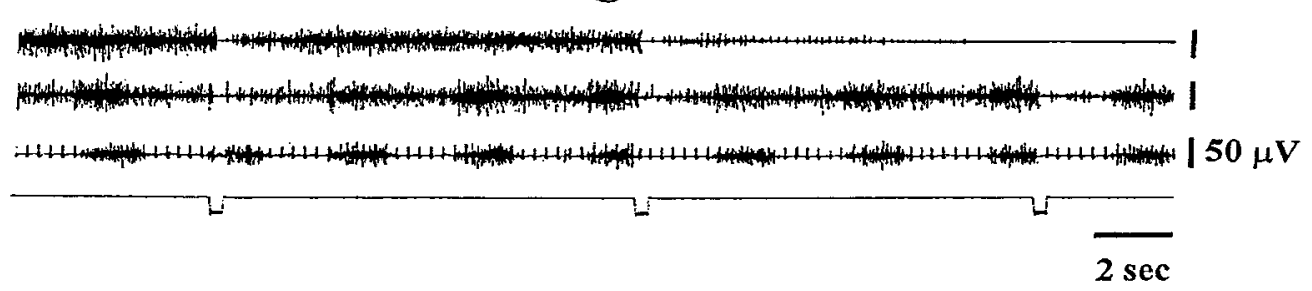

Table 1. Percentage of decrease in norepinephrine and serotonin release in the motoneuron pools and muscle activity during mesopontine inhibitory area stimulation

\begin{tabular}{|c|c|c|c|c|c|c|}
\hline & \multicolumn{2}{|l|}{$\mathrm{NE}$} & \multicolumn{2}{|l|}{ 5-HT } & \multicolumn{2}{|c|}{ Muscle activity } \\
\hline & ES & A & ES & A & ES & A \\
\hline XII & $25.4 \pm 5.55$ & $21.4 \pm 3.09$ & $25.5 \pm 5.71$ & $28.8 \pm 10.70$ & $22.4 \pm 5.7$ & $42.5 \pm 12.4$ \\
\hline $\mathrm{SC}$ & $18.9 \pm 5.69$ & $22.4 \pm 5.92$ & $19.1 \pm 5.32$ & $26.4 \pm 7.00$ & $18.7 \pm 6.8$ & $31.7 \pm 6.9$ \\
\hline
\end{tabular}

A, Acetylcholine injection; ES, electrical stimulation; SC, spinal cord; XII, hypoglossal nucleus.

injection experiment. In the electrical stimulation experiment, eight microdialysis probes were localized to the XII nucleus, with six located at the rostral and the other two located at the caudal part of the nucleus. The remaining three probes were localized to the gigantocellularis nucleus (two cases), and one probe was located in the midline (one case). Seven microdialysis probes were localized in the spinal ventral horn, whereas one site was located in the lateroventral funiculus for the electrical stimulation study. In the Ach injection experiment, all four sites were localized at the XII nucleus, with three located at the rostral and the remaining one site located at the caudal part of the nucleus. In the spinal cord, all five probes were localized to the ventral horn.

\section{Muscle response to electrical stimulation in mesopontine reticular formation}

Electrical stimulation applied in the PIA, PPN, and MRF produced muscle tone suppression in the diaphragm, genioglossus, hindlimb muscles, and bilaterally in the neck muscles. Figure 3 shows the change in EMG activity during brainstem electrical stimulation. In the postural (neck) (Fig. 3) muscle, three types of EMG activity, a brief suppression $(A)$, a prolonged suppression $(B)$, and sustained atonia $(C)$ were found during repetitive mesopontine stimulation. The responses of muscle tone to the mesopontine stimulation were not site- and time-dependent. Stimulation of a single site could produce any type or any two and/or three combinations of muscle activity during a single stimulation period. The percentage decrease of integrated muscle activity in postural muscles during 5 min train stimulation ranged from 5 to $48 \%$ with an average of $18.7 \%$ from the baseline amplitude. In contrast to the postural muscles, mesopontine electrical stimulation never elicited sustained atonia in the respiratory-related muscles. In the genioglossus, mesopontine stimulation generated either a brief suppression (18 of 28 cases) or a prolonged sup- pression (10 of 28 cases) (Fig. 3) of muscle activity. Both inspiratory activity and basal muscle tone of the genioglossus were suppressed by brainstem electrical stimulation. The average reduction of integrated genioglossus muscle activity during the 5 min repetitive brainstem stimulation was $22.4 \%$ from the baseline (Table 1). In the diaphragm, mesopontine electrical stimulation produced a brief suppression of muscle activity. Neither a prolonged suppression of inspiratory amplitude nor sustained atonia was produced in the diaphragm by electrical stimulation of mesopontine inhibitory sites.

Electrical stimulation in the MLB produced ipsilateral facilitation and contralateral inhibition of the postural muscles, with no effect on the respiratory-related muscles. Neither respiratory-related nor postural muscle activity was significantly changed when the stimulation was administered to the LDT and BC.

\section{Muscle response to chemical stimulation in mesopontine reticular formation}

Consistent with our previous study (Lai and Siegel, 1988), Ach microinjected into the PIA suppressed postural muscle tone. Respiratory muscle activity was also suppressed by PIA Ach injection (Fig. 4). Acetylcholine injection into the PIA suppressed both inspiratory activity and basal muscle tone in the diaphragm (Fig. 4) and genioglossus. Both the amplitude and duration of the inspiratory phase of diaphragmatic activity were suppressed by pontine Ach injection. Pontine Ach injection-induced tone suppression had a latency of $47.8 \pm 10.7 \mathrm{sec}$ and duration of $4.8 \pm 0.7$ min in both postural and respiratory-related muscles. The average decrease of muscle tone was $31.7 \%$ in the genioglossus muscle and $42.5 \%$ in postural muscles from the baseline level (Table 1). 
A

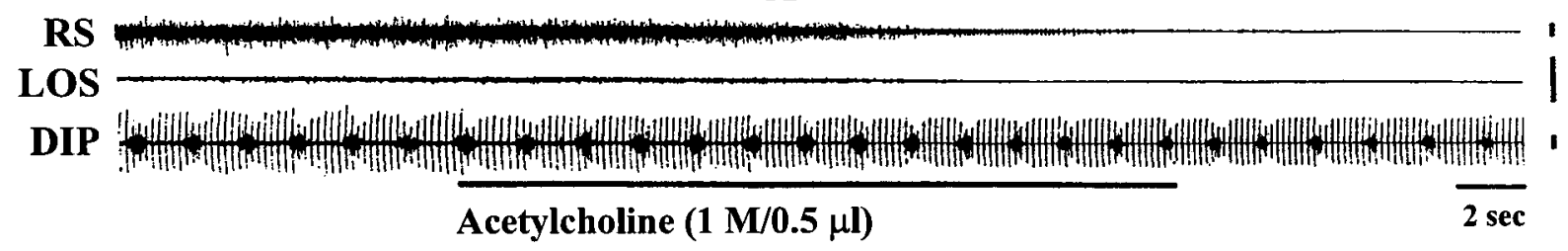

B

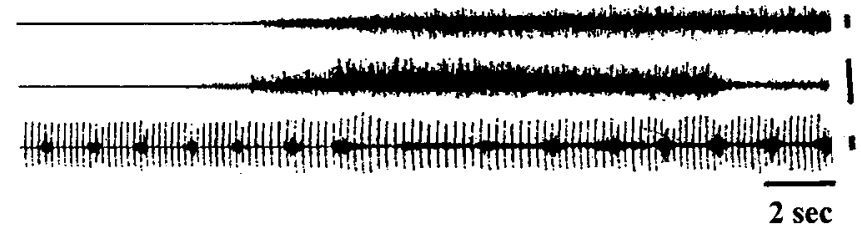

C

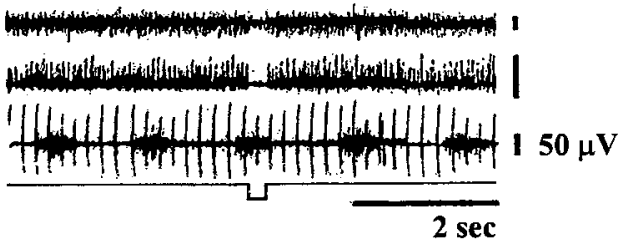

Figure 4. Acetylcholine injection into the PIA induced muscle tone suppression in the postural muscles and diaphragm (DIP). Both tonic and phasic inspiratory activity in the diaphragm were suppressed by the injection. $A$ shows muscle activity before and during acetylcholine injection, $B$ shows recovery of muscle tone, and $C$ shows electrical stimulation into the same site of injection producing muscle tone suppression in both neck muscles and diaphragm. LOS, Left occipitoscapularis muscle; $R S$, right splenius muscle.

\section{Effect of probe insertion}

As with our previous study (Kodama et al., 1998), dialysates were collected 2-3 hr after probe insertion. Dialysates were collected immediately before, during, and after stimulation that induced muscle tone suppression. The effects that were seen could therefore not be attributable to the insertion of the probes themselves. We continued collecting from dialysis sites for a mean of $24 \mathrm{hr}$. Differences between temporally adjacent baseline and stimulation results obtained at the end of this period did not differ from those seen at the beginning. The studies lasted for 18-30 hr.

\section{Norepinephrine release in the hypoglossal nucleus and spinal cord}

We found a reduction of NE release in both sides of the XII nucleus and spinal ventral horn during unilateral electrical stimulation of the PIA, MRF, and PPN that induced muscle tone suppression. Norepinephrine release during electrical stimulation induced muscle tone suppression was significantly reduced from the baseline control levels in the XII nucleus $(p<0.001 ; t=3.2$; $\mathrm{df}=48)$ and spinal ventral horn $(p<0.01 ; t=2.6 ; \mathrm{df}=46)$ (Fig. $5)$. There was no significant difference in the magnitude of the reduction in NE release between the sides ipsilateral and contralateral to the stimulation. Reduction of NE release was of equal magnitude in samples collected from the rostral and caudal XII nucleus. The average percentage reduction of NE release was $25.4 \%$ in the XII nucleus and $18.9 \%$ in the spinal cord (Table 1).

Norepinephrine release in both sides of the XII nucleus $(p>$ $0.9 ; t=0.11 ; \mathrm{df}=13)$ and spinal cord $(p>0.7 ; t=0.335 ; \mathrm{df}=$ 15) was not changed when electrical stimulation was applied to MLB, LDT, and BC sites, at which stimulation produced either unilateral or no effect on muscle activity.

\section{Serotonin release in the hypoglossal nucleus and spinal ventral horn}

Significant decreases in 5-HT release in the XII nucleus $(p<$ $0.05 ; t=3.0 ; \mathrm{df}=50)$ and spinal ventral horn $(p<0.05 ; t=2.3$; $\mathrm{df}=52$ ) (Fig. 5) were found during electrical stimulation in the mesopontine inhibitory area. As with NE, 5-HT release in both ipsilateral and contralateral as well as the rostral and caudal XII nucleus showed a similar reduction. The percentage decrease in

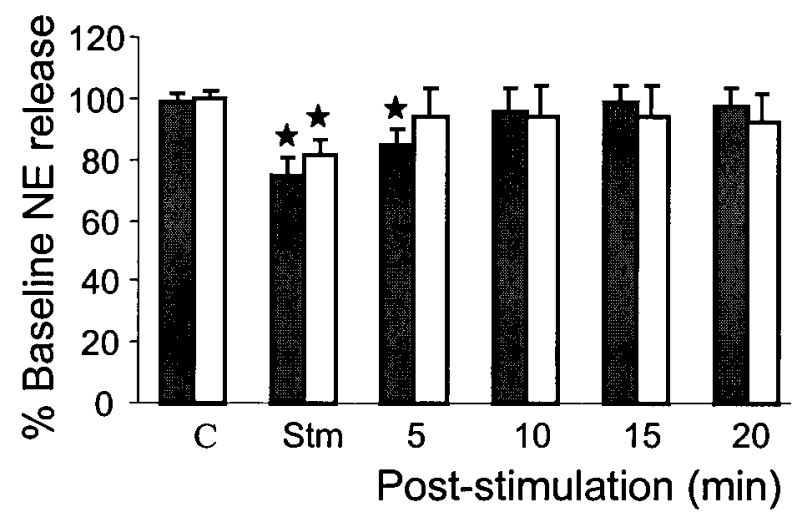

Figure 5. Changes in norepinephrine release in both hypoglossal (black columns) nucleus and spinal ventral horn (white columns). Norepinephrine release was significantly decreased in the hypoglossal nucleus and spinal ventral during electrical stimulation applied into the pontine inhibitory area. Release of norepinephrine recovered to baseline levels by 10 min after stimulation. $C$, Baseline control; Stm, stimulation. $\star p<0.05$.

5-HT release in the XII nucleus and spinal cord was 25.5 and $19.1 \%$, respectively (Table 1 ).

Serotonin release in both sides of XII nucleus $(p>0.7 ; t=$ $0.322 ; \mathrm{df}=9)$ and spinal ventral horn $(p>0.5 ; t=0.693 ; \mathrm{df}=$ 11) was not changed when electrical stimulation was applied to the MLB, LDT, and BC, areas that did not induce muscle tone suppression bilaterally.

\section{Norepinephrine and 5-HT release in the motoneuron pools during PIA Ach-induced muscle tone suppression}

As with electrical stimulation, Ach microinjected into the PIA also produced a significant decrease in NE (spinal cord: $p<0.05$, $t=2.3$, df $=9$; XII nucleus: $p<0.05, t=2.45$, df $=11$ ) and 5-HT (spinal cord: $p<0.05, t=3.07, \mathrm{df}=9$; XII nucleus: $p<0.05, t=$ $2.28, \mathrm{df}=11)$ release in the motoneuron pools. The percentage decrease in NE release in the spinal cord was $22.4 \%$ and in the XII nucleus was $21.4 \%$ (Table 1). Reduction of 5-HT release in the spinal cord was $26.4 \%$ and in the XII nucleus was $28.8 \%$ (Table 1). 


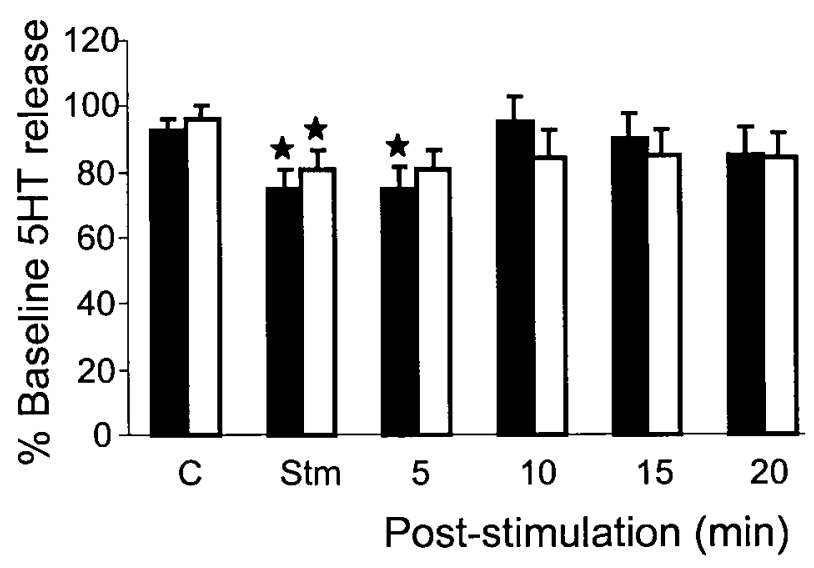

Figure 6. Changes in serotonin release in both hypoglossal (black columns) nucleus and spinal ventral horn (white columns). Serotonin release was significantly decreased in the hypoglossal nucleus and spinal ventral horn during electrical stimulation applied into the pontine inhibitory area. Serotonin release recovered to baseline control levels by 10 min after stimulation. $\star p<0.05$.

\section{Comparison of NE and 5-HT release in the XII nucleus and spinal cord}

We compared the change of NE and 5-HT release in the XII nucleus and spinal cord during mesopontine electrical stimulation over consecutive 5 min epochs. In the XII nucleus, the magnitude of the decrease in NE release was not different $(F=2.97 ; p=$ 0.12 ; $\mathrm{df}=1,10$ ) from that of 5 -HT release during mesopontine stimulation-induced muscle tone suppression. Similarly, no difference in the reduction of NE and 5-HT release $(F=1.85 ; p=$ $0.20 ; \mathrm{df}=1,10)$ in the spinal cord was found during mesopontine electrical stimulation induced decrease in muscle tone. We also compared the XII nucleus and spinal cord NE and 5-HT release during stimulation-induced tone suppression. The magnitude of the decrease in NE release during stimulation was not significantly different between the XII nucleus and spinal cord $(F=$ $0.03 ; p=0.87 ; \mathrm{df}=1,10)$. Similarly, the percentage change of 5-HT release in the XII nucleus and spinal cord was not significantly different $(F=0.19 ; p=0.65 ; \mathrm{df}=1,10)$ with pontine stimulation.

The time course of the reduction of NE and 5-HT release in both spinal cord and XII nucleus was compared. We found that both NE and 5-HT release in the spinal cord returned to a level that was not significantly different from the baseline level after the stimulation, whereas hypoglossal levels remained below baseline for 5 min (Figs. 5, 6).

\section{Dopamine release in the hypoglossal nucleus and spinal cord}

Unlike NE and 5-HT, DA release in the motoneuron pools was unchanged during either electrical stimulation or Ach injection into the mesopontine inhibitory area. Dopamine release in the XII nucleus (electrical stimulation: $p>0.2, \mathrm{df}=15$; Ach injection: $p>0.9, \mathrm{df}=11)$ and spinal cord (electrical stimulation: $p>$ 0.2 , df $=15$; Ach injection: $p>0.7$, df $=9$ ) (Fig. 7) during mesopontine-induced muscle tone suppression was not significantly different from the baseline control level.

\section{DISCUSSION}

In the present study, we found that electrical stimulation of the PIA, PPN, and MRF, and Ach injection into the PIA produced a suppression of postural muscle tone, as reported in our previous

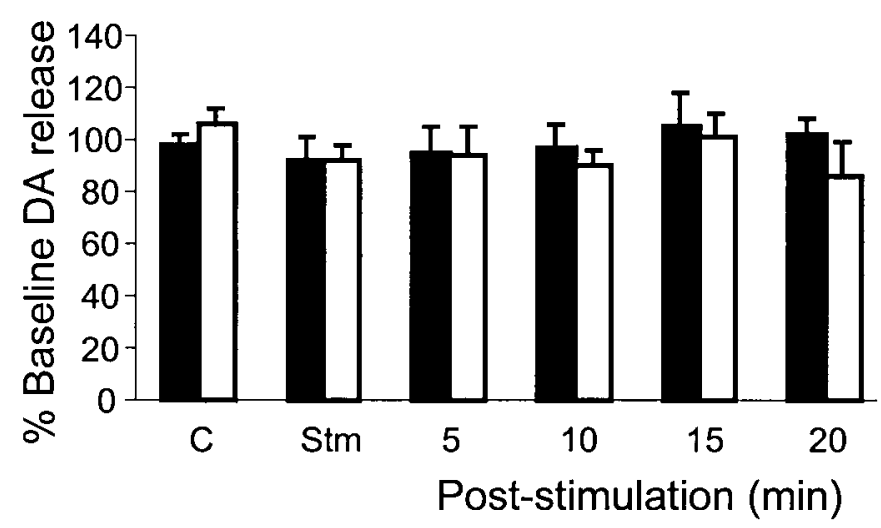

Figure 7. Unchanged dopamine release in the hypoglossal nucleus (black columns) and spinal ventral horn (white columns) during brainstem electrical stimulation induced atonia.

studies (Lai and Siegel, 1988, 1991, 1999). The same stimulation also decreased muscle activity in the genioglossus and diaphragm. We found that mesopontine electrical and chemical stimulationinduced muscle tone suppression was accompanied by a reduction in NE and 5-HT release in both spinal cord and XII nucleus. Although motoneurons innervating the hypoglossus, a tongue retractor, and genioglossus, a tongue protruder, are segregated within the anteroposterior regions of the XII nucleus (Aldes, 1995; Dobbins and Feldman, 1995), the same pattern of NE and 5-HT release suppression was found in the rostral and caudal portions of the XII nucleus during atonia induced by mesopontine stimulation. This result indicates that monoaminergic mechanisms may be equally important in the control of tongue muscles that have opposite physiological function. Previous studies showed that coactivation of the protruder and retractor tongue muscles is required to increase inspiratory flow (Eisele et al., 1997).

Although electrical stimulation in the mesopontine area produced muscle tone suppression in all recorded muscles, the pattern of tone suppression was different in postural and respiratoryrelated muscles. A brief and a prolonged suppression as well as a sustained atonia seen in the present study in postural muscles was consistent with our previous findings in the rat (Hajnik et al., 2000). In contrast to the postural muscles, a sustained atonia was never seen in the genioglossus or diaphragm during repetitive electrical stimulation of the mesopontine region. However, the postural and respiratory muscles had the same latency and the same duration of tone suppression after Ach injection into the PIA.

Kubin et al. (1993) hypothesized that different mechanisms were responsible for the regulation of cranial and spinal motor systems. They suggested that inactivation of the serotonergic system in the XII nucleus and activation of glycinergic mechanism in the spinal cord cause muscle tone suppression in the respiratory and postural muscles during REM sleep, respectively. However, our present finding of decrease in NE and 5-HT release in both XII nucleus and spinal ventral horn during mesopontine stimulation-induced muscle tone suppression indicates that both noradrenergic and serotoninergic systems may play an equal role in the regulation of cranial and spinal motoneuron activity.

We hypothesize that the reduction of NE and 5-HT release in motor nuclei was related to muscle tone change, based on the following considerations. First, the magnitude of reduction of NE and 5-HT release in the motoneuron pools was similar to the percentage decrease in muscle tone. Second, electrical stimula- 
tion in a widespread area of the nervous system, cerebellum, periaqueductal gray, medullary reticular formation, and cortex facilitates noradrenergic and serotoninergic neuron activity (Nakamura et al., 1980; Maciewicz et al., 1984; Morris, 1987). In contrast, we see a reduction of $\mathrm{NE}$ and 5-HT release in the motoneuron pools only during pontine stimulation that produced a suppression of muscle tone. Third, carbachol injection into the PIA produces REM sleep-like activity and simultaneously decreases raphe neuronal activity in the chronic animal and muscle atonia in the decerebrate animal (Steinfels et al., 1983). On the other hand, 5-HT microinfused into the XII nucleus increases genioglossus activity in the rat (Jelev et al., 2001). Fourth, NE and 5-HT have been shown to increase motoneuron excitability in the rat and cat (White and Fung, 1989; Takahashi and Berger, 1990; Berger et al., 1992; Parkis et al., 1995). Microinfusion of NE generates an increase in masseteric reflex in behaving cats (Stafford and Jacobs, 1990). Finally, we did not see a reduction of NE and 5-HT release in the motoneuron pools when electrical stimulation was applied to brainstem areas that failed to produce muscle tone suppression bilaterally.

Several monoaminergic cell groups within the brainstem could be responsible for the changes in monoamine release that we see. Electrical or chemical stimulation of the medullary raphe nucleus increases XII nerve activity (Rose et al., 1995). Electrical stimulation in the LC complex produces an increase in hypoglossal nerve activity (Kuna and Remmers, 1999) and monosynaptic reflex amplitude in the spinal cord (Lai et al., 1989) in decerebrate animals. EPSPs can be seen in spinal motoneurons after stimulation of the LC (Fung and Barnes, 1981, 1987). On the other hand, LC activity is reduced during the natural REM sleep state (Aston-Jones and Bloom, 1981; Hobson et al., 1983) and systemic application of eserine induced REM sleep-like state with atonia in decerebrate cats (Pompeiano and Hoshino, 1976). Locus coeruleus neurons cease discharge during cataplexy, an abrupt loss of muscle tone during waking, seen in the narcoleptic $\operatorname{dog}$ (Wu et al., 1999). Lesions in the LC or injection of clonidine, an $\alpha_{2}$ receptor agonist that inhibits noradrenergic neuron activity, into the LC reduces muscle tone in decerebrate animals (Pompeiano et al., 1987; D'Ascanio et al., 1989). Intracerebroventricular administration of 5,7-dihydroxytryptamine, a 5-HT neurotoxin, decreases muscle tone in the decerebrate rat (Sakai et al., 2000).

Electrical stimulation of a number of nuclei within the mesopontine area, including MRF, PPN, and PIA, has been shown to suppress NE and 5-HT release in the present study. Anatomically, neurons in the MRF, PPN, and PIA project to the medullary raphe nuclei (Gallager and Pert, 1978; Carlton et al., 1983) and LC complex (Sugaya et al., 1988; Kohama, 1992). Alternatively, neurons in the MRF and PPN project to the PIA (Lai et al., 1993), which in turn projects to the monoaminergic nuclei in the brainstem (Gallager and Pert, 1978; Carlton et al., 1983; Sugaya et al., 1988; Kohama, 1992). Monoaminergic projections from the LC complex to the motoneuron pools have been identified (Lai and Barnes, 1985; Aldes et al., 1992). Projections from A5 and A7 (Fritschy and Grzanna, 1990; Aldes et al., 1992) and medullary raphe nuclei (Basbaum and Fields, 1979; Manaker and Tischler, 1993) have also been seen. We hypothesize that activation of the PIA inhibits the activity of noradrenergic and serotonergic neurons that project to the motoneuron pools. Our previous work demonstrated that electrical stimulation in the PIA induces an increase in GABA release in the rodent $\mathrm{LC}$ and decreases discharge in LC neurons (Mileykovskiy et al., 2000). We also found that GABA is released onto $L C$ and raphe neurons during their period of discharge cessation in REM sleep (Nitz and Siegel, 1997a,b). Lesions of the PIA that produce REM sleep without atonia cause dorsal raphe cells, normally silent in REM sleep, to become tonically active during REM sleep (Trulson et al., 1981). Thus, elicitation of atonia in the decerebrate animal is linked to cessation of monoamine release. The reduction in monoamine release along with a simultaneous release of glycine (Kawai and Sasaki, 1964; Chase et al., 1989) and GABA (Bruggencate and Sonnhof, 1972) onto motoneurons would cause hyperpolarization and muscle atonia.

Dopaminergic terminals are present in the spinal ventral horn (Holstege et al., 1996). However, we saw no change of DA release in either XII nucleus or spinal ventral horn during mesopontine stimulation in our present study. Unit recording studies have shown little change in the activity of mesencephalic DA cell across the sleep cycle (Steinfels et al., 1981; Miller et al., 1983) despite the suppression of muscle tone in REM sleep. However, changes in DA release in the motoneuron pools during sleep cannot be ruled out. Terminal release from DA neurons may be independent of somatic action potentials (Verma and Moghaddam, 1998). The hypothalamic A11 group has been identified as a major source of descending dopaminergic input to the motoneuron pools (Hokfelt et al., 1979; Skagerberg and Lindvall, 1985). Unchanged DA release in the motor nuclei during mesopontine stimulation could be attributable to the absence of the hypothalamic A11 group in our decerebrate preparation. Studies in the intact animal would be necessary to test this hypothesis.

In conclusion, we found that the reduction of muscle tone seen in the postural muscles during electrical stimulation of the pons also affects the accessory respiratory musculature. We find decreased release of NE and 5-HT in both XII nucleus and spinal cord during muscle tone suppression. These findings lead us to suggest that mesopontine-induced postural and respiratoryrelated muscle tone suppression is mediated partially through a disfacilitatory effect caused by a reduction in 5-HT and NE release onto motoneurons and that the mechanisms responsible for this link are contained in the brainstem. The tone in the upper airway muscles is minimal in REM sleep (Orem and Lydic, 1978; Remmers et al., 1978). This reduction in tone increases airway resistance in sleep compared with waking (Orem et al., 1977). In individuals with relatively small airways, this leads to sleep apnea (McGinty et al., 1982; Horner, 1996). Pharmacological activation of NE and 5-HT receptors might be a useful approach to increasing airway muscle tone during sleep.

\section{REFERENCES}

Aldes LD (1995) Subcompartmental organization of the ventral (protrusor) compartment in the hypoglossal nucleus of the rat. J Comp Neurol 353:89-108

Aldes LD, Chapman ME, Chronister RB, Haycock JW (1992) Sources of noradrenergic afferents to the hypoglossal nucleus in the rat. Brain Res Bull 29:931-942.

Aston-Jones G, Bloom FE (1981) Activity of norepinephrine-containing locus coeruleus neurons in behaving rats anticipates fluctuations in the sleep-waking cycle. J Neurosci 1:876-886.

Baker RG, Anderson EG (1972) The effect of L-3,4-dihydroxyphenylalanine on spinal reflex activity. J Pharmacol Exp Ther 173:212-223.

Basbaum AI, Fields HL (1979) The origin of descending pathways in the dorsolateral funiculus of the spinal cord of the cat and rat: further studies on the anatomy of pain modulation. J Comp Neurol 187:513-532.

Berger AJ, Bayliss DA, Viana F (1992) Modulation of neonatal rat hypoglossal motoneuron excitability by serotonin. Neurosci Lett 143:164-168. 
Berman AL (1968) The brainstem of the cat. Madison, WI: University of Wisconsin.

Bowker RM, Westlund KN, Sullivan MC, Coulter JD (1982) Organization of descending serotonergic projections to the spinal cord. Prog Brain Res 57:239-265.

Bruggencate G ten, Sonnhof U (1972) Effect of glycine and GABA, and blocking actions of strychnine and picrotoxin in the hypoglossus nucleus. Pflügers Arch 334:240-252.

Carlton SM, Leichnetz GR, Young EG, Mayer DJ (1983) Supramedullary afferents of the nucleus raphe magnus in the rat: a study using the transcannula HRP gel and autoradiographic techniques. J Comp Neurol 214:43-58.

Chase MH, Soja PJ, Morales FR (1989) Evidence that glycine mediates the postsynaptic potentials that inhibit lumbar motoneurons during the atonia of active sleep. J Neurosci 9:743-751.

D'Ascanio P, Pompeiano M, Tononi G (1989) Inhibition of vestibulospinal reflexes during the episodes of postural atonia induced by unilateral lesion of the locus coeruleus in the decerebrate cat. Arch Ital Biol 127:81-97.

Dobbins EG, Feldman JL (1995) Differential innervation of protruder and retractor muscles of the tongue in rat. J Comp Neurol 357:376-394

Eisele DW, Smith PL, Alam DS, Schwartz AR (1997) Direct hypoglossal nerve stimulation in obstructive sleep apnoea. Arch Otolaryngol Head Neck Surg 123:57-61.

Fritschy J-M, Grzanna R (1990) Demonstration of two separate descending noradrenergic pathways to the rat spinal cord: evidence for an intragriseal trajectory of locus coeruleus axons in the superficial layers of the dorsal horn. J Comp Neurol 291:553-582.

Fung SJ, Barnes CD (1981) Evidence of facilitatory coerulospinal action in lumbar motoneurons of cats. Brain Res 216:299-311.

Fung SJ, Barnes CD (1987) Membrane excitability changes in hindlimb motoneurons induced by stimulation of the locus coeruleus in cats. Brain Res 402:230-242.

Fung SJ, Barnes CD (1989) Raphe-produced excitation of spinal cord motoneurons in the cat. Neurosci Lett 103:185-190.

Gallager DW, Pert A (1978) Afferents to brain stem nuclei (brain stem raphe, nucleus reticularis pontis caudalis and nucleus gigantocellularis) in the rat as demonstrated by microiontophoretically applied horseradish peroxidase. Brain Res 144:257-275.

George R, Haslett WL, Jenden DJ (1964) A cholinergic mechanism in the brainstem reticular formation: induction of paradoxical sleep. Int J Neuropharmacol 3:541-552.

Hajnik T, Lai YY, Siegel JM (2000) Atonia related regions in the rodent pons and medulla. J Neurophysiol 84:1942-1948

Henley K, Morrison AR (1974) A re-evaluation of the effects of lesions of the pontine tegmentum and locus coeruleus on phenomena of paradoxical sleep in the cat. Acta Neurobiol Exp 34:215-232.

Hobson JA, McCarley RW, Nelson JP (1983) Location and spike-train characteristics of cells in anterodorsal pons having selective decreases in firing rate during desynchronized sleep. J Neurophysiol 50:770-783.

Hokfelt T, Phillipson O, Goldstein (1979) Evidence for a dopaminergic pathway in the rat descending from the A11 cell group to the spinal cord. Acta Physiol Scand 107:393-395.

Holstege JC, van Dljken H, Buijs RM, Goedknegt H, Gosens T, Bongers CMH (1996) Distribution of dopamine immunoreactivity in the rat, cat, and monkey spinal cord. J Comp Neurol 376:631-652.

Horner RL (1996) Motor control of the pharyngeal musculature and implications for the pathogenesis of obstructive sleep apnea. Sleep 19:827-853.

Jelev A, Sood S, Liu H, Nolan P, Horner RL (2001) Microdialysis perfusion of 5-HT into hypoglossal motor nucleus differentially modulates genioglossus activity across natural sleep-wake states in rats. J Physiol (Lond) 532:467-481.

Jouvet M, Delorme F (1965) locus coeruleus et sommeil paradoxal. C R Soc Biol 159:895-899.

Kawai I, Sasaki K (1964) Effects of strychnine upon supraspinal inhibition. Jpn J Physiol 14:309-317.

Kodama T, Lai YY, Siegel JM (1998) Enhanced glutamate release during REM sleep in the rostromedial medulla as measured by in vivo microdialysis. Brain Res 780:178-181.

Kohama T (1992) Neuroanatomical studies on the urine storage facilitatory areas in the cat brain, part I: input neuronal structures to the nucleus locus subcoeruleus and the nucleus reticularis pontis oralis. Jpn J Urol 83:1469-1477

Kubin L, Kimura H, Tojima H, Davies RO, Pack AI (1993) Suppression of hypoglossal motoneurons during the carbachol-induced atonia of REM sleep is not caused by fast synaptic inhibition. Brain Res 611:300-312.

Kuna ST, Remmers JE (1999) Premotor input to hypoglossal motoneurons from Kolliker-Fuse neurons in decerebrate cats. Respir Physiol 117:85-95.

Lai YY, Barnes CD (1985) A spinal projection of serotonergic neurons of the locus coeruleus in the cat. Neurosci Lett 58:159-164.

Lai YY, Siegel JM (1988) Medullary regions mediating atonia. J Neurosci 8:4790-4796.
Lai YY, Siegel JM (1990) Muscle tone suppression and stepping produced by stimulation of midbrain and rostral pontine reticular formation. J Neurosci 10:2727-2734.

Lai YY, Siegel JM (1991) Pontomedullary glutamate receptors mediating locomotion and muscle tone suppression. J Neurosci 11:2931-2937.

Lai YY, Siegel JM (1999) Muscle atonia and REM sleep. In: Rapid eye movement sleep (Mallick BN, Inoue S, eds), pp 69-90. New Delhi, India: Narosa.

Lai YY, Strahlendorf HK, Fung SJ, Barnes CD (1989) The actions of two monoamines on spinal motoneurons from stimulation of the locus coeruleus. Brain Res 484:268-272.

Lai YY, Clements JR, Siegel JM (1993) Glutamatergic and cholinergic projections to the pontine inhibitory area identified with horseradish peroxidase retrograde transport and immunohistochemistry. J Comp Neurol 336:321-330.

Maciewicz R, Sandrew BB, Phipps BS, Poletti CE, Foote WE (1984) Pontomedullary raphe neurons: intracellular responses to central and peripheral electrical stimulation. Brain Res 293:17-33.

Magoun HW, Rhines R (1946) An inhibitory mechanism in the bulbar reticular formation. J Neurophysiol 9:165-171.

Manaker S, Tischler LJ (1993) Origin of serotoninergic afferents to the hypoglossal nucleus in the rat. J Comp Neurol 334:466-476.

McGinty D, Littner M, Beahm E, Ruiz-Primo E, Young E, Sowers J (1982) Sleep related breathing disorders in older men. Neurobiol Aging 3:337-350.

Mileykovskiy BY, Kiyashchenko LI, Kodama T, Lai YY, Siegel JM (2000) Activation of pontine and medullary motor inhibitory regions reduces discharge in neurons located in the locus coeruleus and the anatomical equivalent of the midbrain locomotor region. $\mathrm{J}$ Neurosci 20:8551-8558.

Miller JD, Farber J, Gatz P, Roffwarg H, German DC (1983) Activity of mesencephalic dopamine and non-dopamine neurons across stages of sleep and waking in the rat. Brain Res 273:133-141.

Morris R (1987) Responses of neurones in the brainstem raphe nuclei to stimulation of the cerebellar fastigial nuclei in the cat. Neurosci Lett 74:19-24.

Nagase Y, Moritani M, Nakagawa S, Yoshida A, Takemura M, Zhang L-F, Kida H, Shigenaga Y (1997) Serotonergic axonal contacts on identified cat trigeminal motoneurons and their correlation with medullary raphe nucleus stimulation. J Comp Neurol 384:443-455.

Nakamura S, Tsai C, Iwama K (1980) Recurrent facilitation of locus coeruleus neurons of the rat. In: The reticular formation revisited (Hobson JA, Brazier MAB, eds), pp 303-315. New York: Raven.

Nitz D, Siegel JM (1997a) GABA release in the dorsal raphe nucleus: role in the control of REM sleep. Am J Physiol 273:R451-R455.

Nitz D, Siegel JM (1997b) GABA release in the locus coeruleus as a function of sleep/wake state. Neuroscience 78:795-801.

Orem J, Lydic R (1978) Upper airway function during sleep and wakefulness: experimental studies on normal and anesthetized cats. Sleep $1: 49-68$.

Orem J, Netick A, Dement WC (1977) Breathing during sleep and wakefulness in the cat. Respir Physiol 30:265-289.

Parkis MA, Bayliss DA, Berger AJ (1995) Actions of norepinephrine on rat hypoglossal motoneurons. J Neurophysiol 74:1911-1919.

Pompeiano O, Hoshino K (1976) Central control of posture: reciprocal discharge by two pontine neuronal groups leading to suppression of decerebrate rigidity. Brain Res 116:131-138.

Pompeiano O, D'Ascanio P, Horn E, Stampacchia G (1987) Effects of local injection of the $\alpha_{2}$-adrenergic agonist clonidine into the locus coeruleus complex on the gain of vestibulospinal and cervicospinal reflexes in decerebrate cats. Arch Ital Biol 125:225-289.

Remmers JE, DeGroot WJ, Sauerland EK, Anch AM (1978) Pathogenesis of upper airway occlusion during sleep. J Appl Physiol 44:931-938.

Rose D, Khater-Boidin J, Toussaint P, Duron B (1995) Central effect of 5-HT on respiratory and hypoglossal activities in the adult cat. Respir Physiol 101:59-69.

Sakai K, Sastre J-P, Kanamori N, Jouvet M (1981) State-specific neurons in the ponto-medullary reticular formation with special reference to the postural atonia during paradoxical sleep in the cat. In: Brain mechanisms and perceptual awareness, (Pompeiano O, Marsan CA, eds), pp 405-429, New York: Raven.

Sakai M, Matsunaga M, Kubota A, Yamanishi Y, Nishsizama Y (2000) Reduction in excessive muscle tone by selective depletion of serotonin in intercollicularly decerebrated rats. Brain Res 860:104-111.

Siegel JM, Nienhuis R, Wheeler RL, McGinty DJ, Harper RM (1981) Discharge pattern of reticular formation unit pairs in waking and REM sleep. Exp Neurol 74:875-891.

Skagerberg G, Lindvall O (1985) Organization of diencephalic dopamine neurons projecting to the spinal cord in the rat. Brain Res 342:340-351.

Soja PJ, Morales FR, Baranyi A, Chase MH (1987) Effect of inhibitory amino acid antagonists on IPSPs induced in lumbar motoneurons upon stimulation of the nucleus reticularis gigantocellularis during active sleep. Brain Res 423:353-358.

Soja PJ, Lopez-Rodriguez F, Morales FR, Chase MH (1991) The 
postsynaptic inhibitory control of lumbar motoneurons during the atonia of active sleep: effect of strychnine on motoneuron properties. J Neurosci 11:2804-2811.

Stafford IL, Jacobs BL (1990) Noradrenergic modulation of the masseteric reflex in behaving cat. J Neurosci 10:91-98.

Steinfels GF, Heym J, Jacobs BL (1981) Single unit activity of dopaminergic neurons in freely moving cats. Life Sci 29:1435-1442.

Steinfels GF, Heym J, Strecker RE, Jacobs BL (1983) Raphe unit activity in freely moving cats is altered by manipulations of central but not peripheral motor systems. Brain Res 279:77-84.

Sugaya K, Mori S, Tsuchida S (1988) Input and output neuronal structures of the pontine micturition center. Part I. Mainly input neuronal structures. Jpn J Urol 79:1210-1218.

Takahashi T, Berger AJ (1990) Direct excitation of rat spinal motoneurones by serotonin. J Physiol (Lond) 423:63-76.

Trulson ME, Jacobs BL, Morrison AR (1981) Raphe unit activity dur- ing REM sleep in normal cats and in pontine lesioned cats displaying REM sleep without atonia. Brain Res 226:75-91.

Van Dongen PAM, Broekkamp CLE, Cools AR (1978) Atonia after carbachol microinjections near the locus coeruleus in cats. Pharmacol Biochem Behav 8:527-532.

Verma A, Moghaddam B (1998) Regulation of striatal dopamine release by metabotropic glutamate receptors. Synapse 28:220-226.

White SR, Fung SJ (1989) Serotonin depolarizes cat spinal motoneurons in situ and decreases motoneuron afterhyperpolarizing potentials. Brain Res 502:205-213.

Wu M-F, Gulyani SA, Yau E, Mignot E, Phan B, Siegel JM (1999) Locus coeruleus neurons: cessation of activity during cataplexy. Neuroscience 91:1389-1399.

Yamuy J, Fung SJ, Xi M, Morales FR, Chase MH (1999) Hypoglossal motoneurons are postsynaptically inhibited during carbachol-induced rapid eye movement sleep. Neuroscience 94:11-15. 